\title{
DR-20. INTERACTION OF 3- AND 6-UNSUBSTITUTED 1,2,4-TRIAZINES WITH LITHIUM SALT OF PHENYLACETYLENE
}

\author{
A. F. Khasanov ${ }^{1,2}$, D. S. Kopchuk ${ }^{1,2}$, I. S. Kovalev ${ }^{1}$, A. P. Krinochkin ${ }^{1,2}$, \\ G. V. Zyryanov ${ }^{1,2}$, V. L. Rusinov ${ }^{1,2}$, O. N. Chupakhin ${ }^{1,2}$ \\ ${ }^{1}$ Ural Federal University of the first President of Russia B. N. Yeltsin, \\ Mira St., 19, Yekaterinburg, 620002, Russia \\ ${ }^{2}$ I. Ya. Postovsky Institute of Organic Synthesis UB RAS, \\ S. Kovalevskoy/Akademicheskaya St., 20/22, Yekaterinburg, 620990, Russia \\ E-mail: a.f.khasanov@ya.ru
}

The main synthetic techniques for introducing stilbene and acetylenes moieties into the structure of various heterocycles are Pd-catalyzed Sonograshira and Heck reactions. The starting compounds are the corresponding halogen derivatives. However, in some cases, a number of examples for the preparation of such compounds as a result of $\mathrm{C}-\mathrm{H}$ functionalization, both catalyzed and non-catalyzed ones, have been described in the literature. Due to the adherence to the principles of the atomic economy the second approach is of wide interest. In particular, the methodology of nucleophilic substitution of hydrogen can be used for this. It is necessary to note the reported examples of deoxygenative $\mathrm{S}_{\mathrm{N}}^{\mathrm{H}}$ in the series of azines $\mathrm{N}$-oxides. Recently, our research group showed the possibility of obtaining 1,2,4-triazines with the residue of styryl at position $\mathrm{C} 5$ as a result of the interaction of the corresponding 5-H-triazines with the lithium salts of arylacetylenes. In this paper, we present the results of similar reactions for 6-and 3-unsubstituted 1,2,4-triazines.
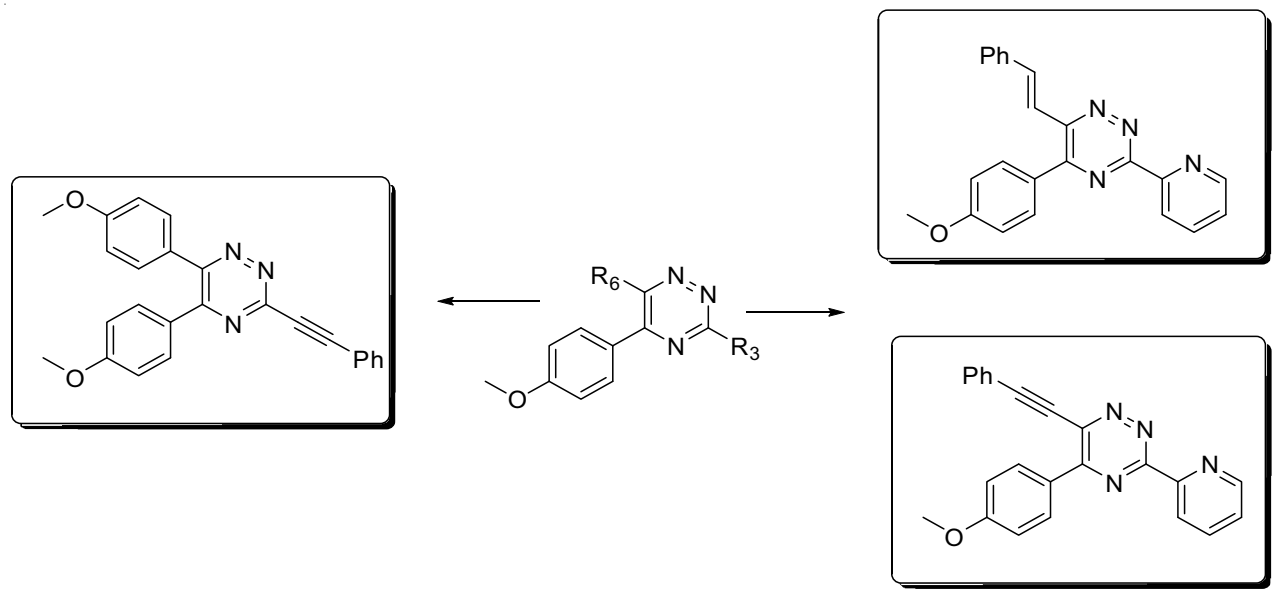

This work was supported by the Russian Science Foundation (Ref. № 18-13-00365). 